\title{
CORRELATION OF PLACENTAL THICKNESS ESTIMATED BY ULTRASONOGRAPHY WITH GESTATIONAL AGE IN THE SECOND AND THIRD TRIMESTER OF PREGNANCY
}

\author{
By \\ Hamada Ali Abou Zeid, Mofeed Fawzy Mohamed and Wael Soliman \\ Taha \\ Department of Obstetrics and Gynecology, Faculty of Medicine Al-Azhar University \\ E-mail: hamadaabouzeid@gmail.com
}

\begin{abstract}
Background: Normal development of placenta during gestation is necessary for supporting of a healthy fetus. On the other hand, any impairment in its development may have a profound impact on fetal development and pregnancy outcome.

Objective: To study the placental thickness by ultrasonography in relation to gestational age (GA).

Patient and Methods: The present prospective study was conducted on 100 pregnant females attending antenatal clinics in both Damanhour Educational Hospital and Eldelngat central Hospital in the period from August 2018 to August 2019. The placental thickness in mm was measured at the level of cord insertion site. Placental thickness was calculated from the echogenic chorionic plate to placental myometrial interface near the mid-placental portion.

Results: There was a positive correlation between increase in placental thickness ( $\mathrm{mm}$ ) in total sample, 2nd trimester, and 3rd trimester and GA, as GA increase Placental thickness increase.

Conclusion: Placental thickness measured at the level of umbilical cord insertion can be used as an accurate sonographic indicator in the assessment of gestational age because of its linear correlation. Therefore, it can be used as an additional sonographic tool in correlating gestational age in cases where last mestrual period (LMP) is not known and in detecting patients developing intrauterine growth retardation (IUGR).
\end{abstract}

Keywords: Gestational age, Placental thickness, Intrauterine growth retardation.

\section{INTRODUCTION}

Obstetric ultrasonography offers the tools to estimate fetal weight and assess placental size (Mull et al., 2018). Placental thickness is the easiest placental dimension measure. Yet, little is known about the "normal" placental thickness as measured by sonography. Historically, a placenta of greater than $4 \mathrm{~cm}$ in thickness has been regarded as abnormal and associated with various poor outcomes (Sersam et al., 2016).

Placental thickness is very much related to fetal development and may be a key in perinatal outcome at term placenta is approximately $3 \mathrm{~cm}$ thick and measures $15-25 \mathrm{~cm}$ in diameter (BaGhel et al., 2015). A 'warning limit' of placental diameter of $18 \mathrm{~cm}$ and placental thickness of $2 \mathrm{~cm}$ at 36 weeks predict low birth weight neonates (Abdelhamid et al., 
2019). Small placentas are associated with preeclampsia, chromosomal abnormalities, severe maternal diabetes mellitus, chronic fetal infections and intrauterine growth restriction (BaGhel et al., 2015). The placentas over $4 \mathrm{~cm}$ thick at term have been observed in conditions like diabetes mellitus, perinatal infections and hydrops fetalis (Vinodha, 2016).

The incidence of perinatal morbidity and mortality was considerably higher among gravid with thick placenta, related to higher rates of fetal anomalies and higher rates of both small for gestational age and large for gestational age neonates at term (Norris et al., 2015).

Increased placental thickness is not diagnostic of any specific disorder but may contribute to the management of fetus at risk. The gestational age is frequently overestimated or underestimated, as many people are unaware of LMP and irregular menstrual cycle (Batstone et al., 2012).

\section{PATIENTS AND METHODS}

The present prospective study was conducted on 100 pregnant females attending antenatal clinics in both Damanhour Educational Hospital and Eldelngat central Hospital in the period from August 2018 to August 2019 after taking ethical committee clearance from Institutional Ethical Committee. The study was explained to the study population, and a written consent was obtained from each patient.

\section{Inclusion criteria:}

Singleton pregnancy, gestational age more than 13 week, known last menstrual period, a history of regular menstruation, and age group of 20 - 35 years.

\section{Exclusion criteria:}

Gestational hypertension, diabetes mellitus, hydrops fetalis, congenital malformations, twins, polyhydramnios, last menstrual period not known irregular menstrual period, abnormal placenta, and poor visualization of placenta.

The placental thickness in $\mathrm{mm}$ was measured at the level of cord insertion site. Placental thickness was calculated from the echogenic chorionic plate to placental myometrial interface near the mid-placental portion. All placental measurements were taken during the relaxed phase of the uterus as contractions can spuriously increase the placental thickness.

Placental thickness value, in mm, was calculated by averaging the three best measurements for each case.

Umbilical artery color Doppler was used for further reconfirmation of the site of umbilical cord insertion. The placental thickness was measured transabdominally by using Madison color Doppler scanner with a $3.5-\mathrm{MHz}$ convex transducer placing it perpendicularly to the plane of the placenta.

\section{Statistical analysis of the data:}

Data were fed to the computer and analyzed using IBM SPSS software package version 20.0. (Armonk, NY: IBM. Corp) Qualitative data were described using number and percent. The Kolmogorov-Smirnov test was used to verify the normality of distribution. Quantitative data were described using range (minimum and maximum), mean, 
standard deviation and median. judged at the 5\% level.

Significance of the obtained results was

\section{RESULTS}

In the present study, age of patients ranged between 20.0 - 35.0 years with a mean age of $29.35 \pm 2.94$ years in the present study. Patients $<25$ were $6(6.0 \%)$, Patients $25-30$ were $58(58.0 \%)$, and Patients $>30$ were $36(36.0 \%)$. GA ranged between 18.0 - 38.0 weeks with a mean age of $28.34 \pm 4.44$ weeks in the present study. Patients $\leq 26$ ( $2^{\text {nd }}$ trimester) were 30 $(30 \%)$ and Patients $>26\left(3^{\text {rd }}\right.$ trimester $)$ were $70(70.0 \%)$ (Table 1).

Table (1): Distribution of the studied cases according to age, GA and Placental thickness

\begin{tabular}{|l|c|c|}
\hline Age & No. & \% \\
\hline$<25$ & 6 & 6.0 \\
\hline $25-30$ & 58 & 58.0 \\
\hline$>30$ & 36 & 36.0 \\
\hline Min. - Max. & \multicolumn{2}{|c|}{$20.0-35.0$} \\
\hline Mean \pm SD. & \multicolumn{2}{|c|}{$29.35 \pm 2.94$} \\
\hline GA & No. & \% \\
\hline$\leq 26\left(2^{\text {nd }}\right.$ trimester $)$ & 30 & 30.0 \\
\hline$>26\left(3^{\text {rd }}\right.$ trimester $)$ & 70 & 70.0 \\
\hline Min. - Max. & \multicolumn{2}{|c|}{$18.0-38.0$} \\
\hline Mean \pm SD. & $28.34 \pm 4.44$ \\
\hline Placental thickness $(\mathbf{m m})$ & No. & \% \\
\hline$<30$ & 4 & 4.0 \\
\hline$\geq 30$ & 96 & 96.0 \\
\hline Min. - Max. & \multicolumn{2}{|c|}{$25.0-43.0$} \\
\hline Mean \pm SD. & \multicolumn{2}{|c}{$36.03 \pm 3.29$} \\
\hline
\end{tabular}

In the present study, there was a positive correlation between increase in Placental thickness $(\mathrm{mm})$ in Total sample, 2nd trimester, and 3rd trimester and GA, as GA increase Placental thickness increase. The mean GA $\leq 26$ was $34.93 \pm$
3.57 and mean GA > 26 were $36.50 \pm 3.07$. As GA increase Placental thickness increase. In our study, a significant positive correlation is seen between placental thickness and the gestational age (Table 2).

(Table 2): Correlation between GA and Placental thickness

\begin{tabular}{|l|c|c|}
\hline \multirow{2}{*}{ Placental thickness $(\mathbf{m m})$} & \multicolumn{2}{|c|}{ GA } \\
\cline { 2 - 3 } & $\mathbf{r}$ & $\mathbf{p}$ \\
\hline Total sample & $0.413^{*}$ & $<0.001^{*}$ \\
\hline $\mathbf{2}^{\text {nd }}$ trimester & $0.714^{*}$ & $<0.001^{*}$ \\
\hline $\mathbf{3}^{\text {rd }}$ trimester & $0.242^{*}$ & $0.044^{*}$ \\
\hline
\end{tabular}

r: Pearson coefficient 


\section{DISCUSSION}

The placenta is a fetal organ which provides the physiologic link between a pregnant woman and the fetus. The placenta develops from the chorionic villi at the implantation site at about the fifth week of gestation and by the ninth or tenth week, the diffuse granular echo texture of the placenta is clearly apparent at sonography (Amy Jnah and Trembath, 2019).

Placental thickness appears to be a promising parameter for estimation of GA of the fetus because of increase in placental thickness with GA (Korzeniewski et al., 2016).

In the present study, there was a positive correlation between increase in Placental thickness (mm) in Total sample, 2nd trimester, and 3rd trimester and GA, as GA increase Placental thickness increase. The mean GA $\leq 26$ was $34.93 \pm$ 3.57 and mean GA > 26 were $36.50 \pm 3.07$. As GA increase Placental thickness increase. Accurate determination of gestational age has become important for deciding the appropriate time for termination of the pregnancy as well as to monitor the fetal growth during the entire period of pregnancy. In addition to the routine fetal biometry parameters, various studies were done trying to deduce a relationship between the placental thickness and gestational age and the estimated fetal weight (Mathai et al., 2013).

A fairly linear increase in mean placental thickness with gestational age was observed in correlation analysis studies conducted to determine the relationship between placental thickness and gestational age (Mahale et al., 2018).
The value of the mean placental thickness increased with advancing gestational age, almost matching from the 22nd to the 35th week and 27 to 33 weeks (Kakumanu et al., 2018). Significant positive correlations between placental thickness and estimated fetal weight in the second and third trimesters $(\mathrm{p}<0.05)$ in a nonIUGR group were also demonstrated (Mathai et al., 2013). A positive correlation, with increasing placental volume with increasing gestational age, was also observed, but it remained reduced in the growth-restricted fetuses (Krishna and Bhalerao, 2011). The usefulness of this relationship between placental thickness and growth parameters is that subnormal placental thickness for a gestational age may be the earliest indication of fetal growth retardation (Mathai et al., 2013).

In our study, a significant positive correlation is seen between placental thickness and the ultra sonographic gestational age. (Babiker and Eisa, 2014) compared the fetal age progress and the placenta thickness in pregnant women. In a cross sectional descriptive study, one thousand pregnant women with mean age of 29 years old, were examined by ultrasound imaging. In the $\left(12^{\text {th }}-25^{\text {th }}\right)$, $\left(26^{\text {th }}-36^{\text {th }}\right)$ and $\left(37^{\text {th }}-40^{\text {th }}\right)$ Weeks the GA were; $18.9 \pm 4.2,33.2 \pm 2.9$ and $38.1 \pm$ 0.89 respectively. While the placenta thickness measurements were; $23.1 \mathrm{~mm} \pm$ $5.5,35.0 \mathrm{~mm} \pm 6.2$ and $39.6 \mathrm{~mm} \pm 7.0$ respectively for the same periods. The highest frequency of placenta grading was Grade2 which is $(36.0 \%$ of 1000$)$. The highest frequency of placental location was Anterior Fundal which is $(22.1 \%$ of 1000). There was strong statistical association between the increasing of 
placenta thickness and the GA, $\mathrm{P}=0.000$. The placenta thickness measurements can be carried on consideration with the other GA measurements parameters.

Placental thickness ranged between $25.0-43.0 \mathrm{~mm}$ with a mean thickness of $36.03 \pm 3.29$ in the present study. Patients $<30$ were $(4 \%)$ and Patients $\geq 30$ were 96 $(96.0 \%)$. This study revealed a maximum placental thickness of $39.26 \pm 5.69 \mathrm{~mm}$ at 40 weeks. This value is similar to that of (Ville and Bault, 2016) in the United States who reported that normal placenta never exceeded $40 \mathrm{~mm}$ in thickness throughout pregnancy. A slightly lower value of $37.5 \mathrm{~mm}$ at 39 weeks was reported by (Ali, 2018). This shows that race apparently has no influence on placenta measurements.

\section{CONCLUSION}

It can be concluded that, Placental thickness measured at the level of umbilical cord insertion can be used as an accurate sonographic indicator in the assessment of gestational age because of its linear correlation. Therefore, it can be used as an additional sonographic tool in correlating gestational age in cases where last mestrual period (LMP) is not known and in early detecting patients developing intrauterine growth retardation (IUGR).

\section{REFERENCES}

1. Abdelhamid, A. N., Sayyed, T. M., Shahin, A. H. E., and Zerban, M. A. (2019): Correlation between second and third trimester placental thickness with ultra sonographic gestational age. Menoufia Medical Journal, 32(4): 1406-1410.

2. Ali, R. K. E. (2018): A Study of Relationship between Placental Thickness and Fetal Age In 3rd trimester in Sudanese Women. Sudan University of Science and Technology, 110(3): 231-234.
3. Amy Jnah, D. and Trembath, A. N. (2019): Fetal and neonatal physiology for the advanced practice nurse: Springer Publishing Company, 24(4):25-29.

4. Babiker, M. S. and Eisa, R. A. (2014): Placenta thickness measurements during gestational age progress. Journal of Applied Medical Sciences, 3(6):31-37.

5. BaGhel, P., Bahel, V., Paramhans, R., Sachdev, P. and Onkar, S. (2015): Correlation of placental thickness estimated by ultrasonography with gestational age and fetal outcome. Indian Journal of Neonatal Medicine and Research, 3(5): 19-24.

6. Batstone, G. F., Blair, A. W. and Slater, J. M. (2012): A Handbook of Pre-Natal Paediatrics for Obstetricians and Pediatricians: Springer Science and Business Media, 5(9): 211-220.

7. Kakumanu, P. K., Kondragunta, C. and GandraNR, Y. H. (2018): Evaluation of placental thickness as an ultrasonographic parameter for estimating gestational age of the fetus in 2nd and 3rd trimesters. International Journal of Contemporary Medicine Surgery and Radiology, 3(1): 128132.

8. Korzeniewski, S. J., Romero, R., Chaiworapongsa, T., Chaemsaithong, P., Kim, C. J., Kim, Y. M. and Yeo, L. (2016): Maternal Plasma Angiogenic Index-1 (PIGF/sVEGFR-1) is a Biomarker for the Burden of Placental Lesions Consistent with Uteroplacental Under perfusion: a Longitudinal Case-Cohort Study. American Journal of Obstetrics and Gynecology, 214(5): 629-621.

9. Krishna, U., and Bhalerao, S. (2011): Placental insufficiency and fetal growth restriction. The Journal of Obstetrics and Gynecology of India, 61(5): 505-511.

10. Mahale, N., Mitra, M., Mahale, A., Fernandes, M., and Ullal, S. (2018): Placental thickness and its correlation with gestational age and foetal growth parameters. Italian Journal of Obstetrics and Gynecology, 40(1): 33-41. 
11. Mathai, B. M., Singla, S. C., Nittala, P. P., Chakravarti, R. J., and Toppo, J. N. (2013): Placental thickness: its correlation with ultra sonographic gestational age in normal and intrauterine growth-retarded pregnancies in the late second and third trimester. The Journal of Obstetrics and Gynecology of India, 63(4): 230-233.

12. Mulla, B. M., Noor, N., James-Todd, T., Isganaitis, E., Takoudes, T. C., Curran, A. and Brown, F. M. (2018): Continuous glucose monitoring, glycemic variability, and excessive fetal growth in pregnancies complicated by type 1 diabetes. Diabetes Technology and Therapeutics, 20(6): 413419.

13. Norris, T., Johnson, W., Farrar, D., Tuffnell, D., Wright, J., and Cameron, N.
(2015): Small for gestational age and large for gestational age thresholds to predict infants at risk of adverse delivery and neonatal outcomes. BMJ Open, 5(3): 67-73.

14. Sersam, L. W., Abdul-Razzak, Z. Z., and Mohammed, S. Y. (2016): Second and Third Trimester Placental Thickness: Correlation with Placental and Birth Weights. Iraqi Postgraduate Medical Journal, 15(4): 42-46.

15. Ville, Y. G., and Bault, J.-P. (2016): 13 Prenatal Diagnoses of Fetal Malformations by Ultrasound. Genetic disorders and the fetus, 5(4): 121-126.

16. Vinodha, M. (2016): Ultra sonographic Placental Thickness: Its Correlation to Gestational Age. ESIC Medical College and PGIMSR, Chennai, 7(5): 438-443. 
در اسة الإرتباط بين سمك المشيمة المقدر بو اسطة الموجات

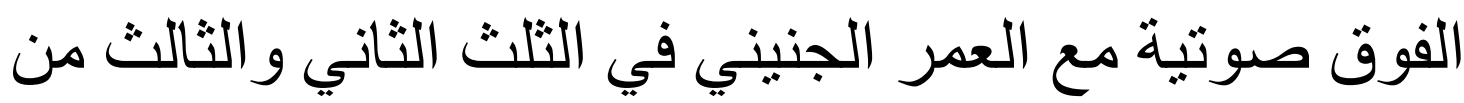
الحمل

حمادة علي أبوزيد، مفيد فوزي محمد، وائل سليمان طه قسم التوليد وأمراض النساء، كلية الطب جامعة الأزهر

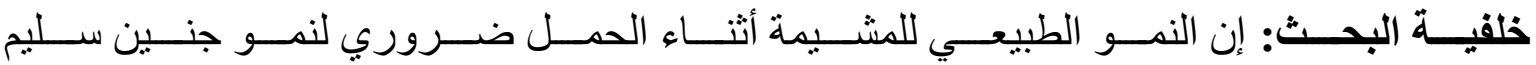
وقد يكون لأي ضعف في نمو المشيمه نأثيراً عميقاً على نمو الجنين ونتائج الحمل.

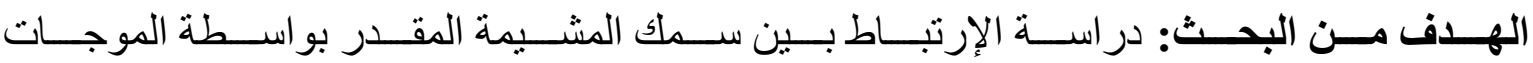
الفوق صوتية مع العمر الجنيني في الثلث الثاني و الثالث من الحمل.

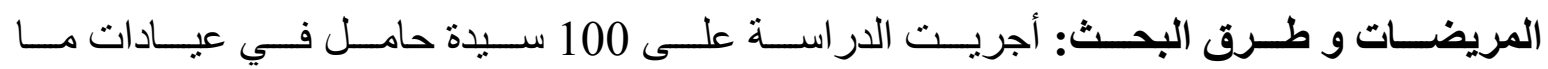

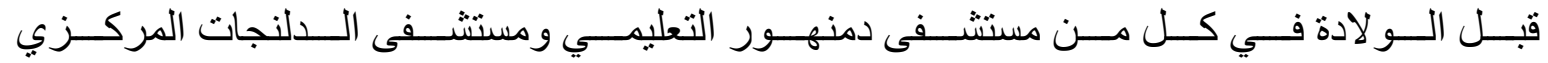

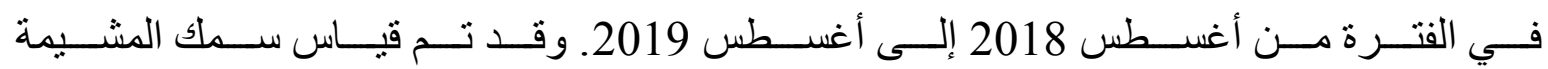

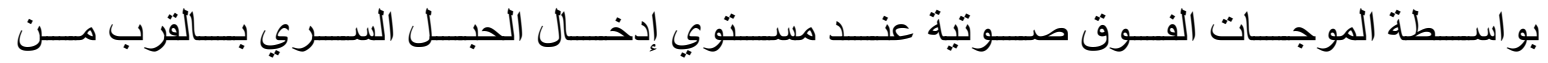
منتصف المشيمة.

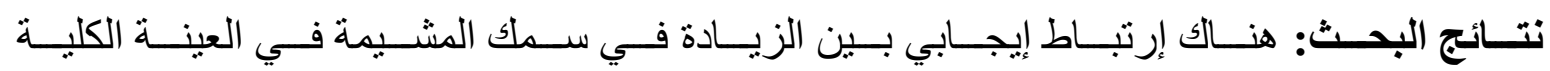
و العمر الجنيني، حيث أنه كلما زاد العمر الجنيني زاد سمك المشيمة.

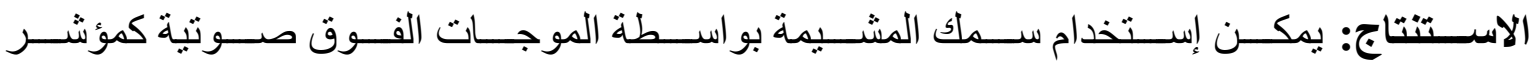

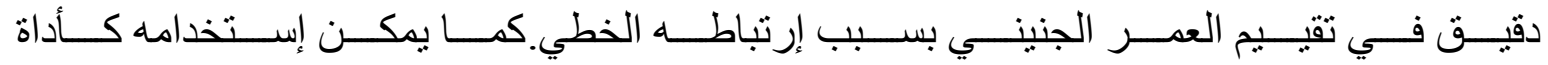

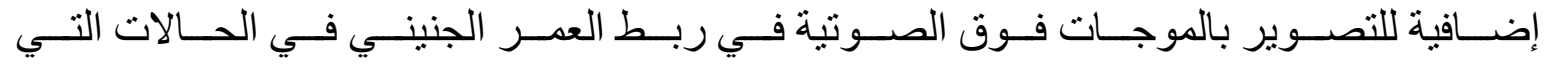

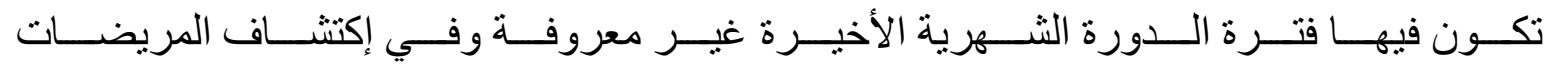
اللاتى تصبن بتخلف النمو داخل الرحم. 